\title{
Sedentary lifestyle and Framingham risk scores: a population-based study in Riyadh city, Saudi Arabia
}

\author{
AlJohara M. AlQuaiz ${ }^{1,2}$, Amna Rehana Siddiqui ${ }^{1,2}$, Ambreen Kazi ${ }^{1,2^{*}}$ (D, Mohammad Ali Batais ${ }^{2}$ and Ali M. Al-Hazmi ${ }^{2}$
}

\begin{abstract}
Background: Studies from Saudi Arabia have reported a continued increase in the prevalence of cardiovascular diseases and their associated risk factors. The objective of this study was to measure the gender differences in the cardiovascular disease (CVD) risk based on Framingham risk scores (FRS) and to explore the association of FRS with sedentary life style including physical inactivity, sitting time and central obesity among Saudi adults.
\end{abstract}

Methods: A cross-sectional survey was conducted on 2997 Saudi adults (males $=968$, females $=2029$ ) selected from 18 primary health care centres in Riyadh city, from December 2014 to August 2015. A detailed interview that evaluated lifestyle and past medical history was conducted; furthermore, anthropometric measurements and blood samples were collected for lipid profiling. The FRS were calculated based on the age, gender, systolic blood pressure, treatment for hypertension, diabetes, smoking status, total blood cholesterol and high-density lipoprotein levels. These scores were categorized into low risk (FRS $<10)$ and high/intermediate risk $(\geq 10)$. A multivariable logistic regression analysis was performed.

Results: The mean $( \pm \mathrm{SD})$ age of the males and females was $43.1( \pm 11.7)$ vs $43.8( \pm 10.9)$ years $(p=0.07)$, respectively. The number of Saudi male participants with intermediate-to-high FRS scores $(\geq 10)$ was almost twice that of females (males 33\% vs 17\%). The multivariable logistic regression model after adjusting for education level and housing type, found that low physical activity (aOR \& 95\%Cl for males 2.91 (1.45, 5.80); females 1.38 (1.06, 1.81); prolonged sitting time (aOR \&95\%Cl for males $1.36(0.98,1.90)$ females $1.58(1.20,2.07)$, high central obesity (defined as waist circumference in males $>102 \mathrm{cms}$, and females $>88 \mathrm{cms}$ ) (aOR \& 95\%Cl for males $2.38(1.67,3.41)$; females $3.35(1.92,5.87)$ were associated with high/ intermediate risk for CVD.

Conclusions: A significant percentage of Saudi population revealed FRS $\geq 10$. Females beyond the age of 50 were found to have a higher prevalence for CVD risk compared with males of the same age group. Modifiable risk factors like low physical activity, prolonged sitting time and central obesity have strong implications for primary prevention and management services that can change the risk profile of the Saudi population.

Keywords: Framingham risk scores, cardiovascular disease risk, Physical inactivity, Sitting time, Waist circumference

\footnotetext{
* Correspondence: akamran@ksu.edu.sa

${ }^{1}$ Princess Nora Bent Abdallah Research Chair for Women Health Research,

Deanship of Research Chairs program, King Saud University, Riyadh, Kingdom of Saudi Arabia

${ }^{2}$ Department of Family \& Community Medicine, College of Medicine, King

Saud University, Riyadh, Kingdom of Saudi Arabia
}

(C) The Author(s). 2019 Open Access This article is distributed under the terms of the Creative Commons Attribution 4.0 International License (http://creativecommons.org/licenses/by/4.0/), which permits unrestricted use, distribution, and reproduction in any medium, provided you give appropriate credit to the original author(s) and the source, provide a link to the Creative Commons license, and indicate if changes were made. The Creative Commons Public Domain Dedication waiver (http://creativecommons.org/publicdomain/zero/1.0/) applies to the data made available in this article, unless otherwise stated. 


\section{Background}

Cardiovascular disease (CVD) accounts for $31 \%$ of all global deaths, and more than 18 million people die from CVD-related causes annually [1]. CVD is an increasing public health concern in the Middle East and the Gulf Council Countries (GCC) [2-4]. It is estimated that the overall deaths from CVD in the GCC countries, including Saudi Arabia, represent over $45 \%$ of all deaths [1]. It is projected that the prevalence of CVD in the Kingdom of Saudi Arabia (KSA) will rapidly increase in the future [5].

Different International studies, such as The INTERSTROKE and INTERHEART studies [6, 7], the Gulf Registry of acute coronary events (Gulf RACE) [2] and the Africa Middle East Cardiovascular Epidemiological (ACE) study [8] have, all recognized a common set of risk factors that are associated with CVD. These factors include hypertension, diabetes mellitus, dyslipidaemia, obesity, smoking, physical inactivity, poor dietary habits, and alcohol consumption [2]. The modifiable risk factors, collectively accounted for 90 and $94 \%$ population attributable risk in males and females, respectively [7]. Studies from Saudi Arabia have also reported that the prevalence of these risk factors are on the rise during each consecutive year [9-11]. Varying results on gender differences have been reported by the previous research studies in context to CVD prevalence and the associated factors. [2-4]. The prevalence of CVD has been found to be higher in males as compared to the females [2-4]. Majority of the studies report that factors like diabetes mellitus, hypertension, physical inactivity and smoking were more prevalent among the males as compared to the males. Whereas, overweight and obesity was more commonly reported among the females [2-11].

Over the past few decades, many studies have shown that individuals leading sedentary lifestyles have higher levels of CV risk factors and an increased risk of incident CVD $[12,13]$. A study by Chau et al. demonstrated that adults who sit for $\geq 10$ hours/day (h/day) had a $65 \%$ and $115 \%$ greater risk of overall and cardio-metabolic-related mortality, respectively, compared to those with a sitting time of $<4 \mathrm{~h} /$ day after adjusting for potential confounders (age, smoking, physical activity, body mass index, education level, health status and cardio-metabolic disease status with age) [12]. Similarly, another study demonstrated that a longer duration of total daily sitting time ( $>10 \mathrm{~h}$ compared to $<6 \mathrm{~h} /$ day) can increase the risk of myocardial infarction (MI) by $38 \%$ and the overall risk of mortality by $31 \%$ [14]. In Saudi Arabia, physical inactivity received attention during the last decade with studies showing an alarmingly high number of adults (ranging from $75 \%$ to $90 \%$ ) reporting less than sufficient levels of physical activity [15-18].

Many risk-assessment tools are available [19-24], which can objectively measure the impact of various $\mathrm{CV}$ risk factors and provide an estimate of CV risk [2, 24-26]. Subsequently, these can be used to guide the development of disease prevention strategies and management interventions for patients at a high risk of CVD [25, 26]. Among these tools, the Framingham risk score (FRS) is the most frequently used tool $[21,23]$. The clinical practice guidelines for the primary prevention of coronary heart disease (CHD) also recommend a risk management approach based on the FRS [27]. The FRS is available in various application formats, such as point scoring systems, risk charts, or web-based calculators [28].

The Framingham heart study, conducted by $\mathrm{Al}$ Humaidi, in Abha province, KSA, have reported a mean risk of $8.9 \%$ for developing coronary artery disease [29]. Another recent study that was conducted among the military population, which were expected to have higher fitness level, revealed that one-tenth of the participants had a 10 -year CVD risk of $\geq 10 \%$, with a mean risk of $4.5 \%$ [30]. However, the probability of 10 year-CVD risk based on the FRS and its association with sedentary life style in the general Saudi population remains largely unknown. Hence, the objective of this study was to measure the gender differences in the probability of 10-year risk for CVD based on the FRS and to examine the association of FRS with sedentary lifestyles among Saudi males and females aged 30 to 75 years.

\section{Methods \\ Study design and setting}

This study was part of a large cross-sectional survey (Women in Saudi Arabia Health Examination Survey; WISHES), which aimed to measure the prevalence, severity and factors correlated with various chronic diseases in males and females aged 30 to 75 years in Riyadh city, Saudi Arabia. Data were collected between December 2014 to August 2015. There are 105 primary health care centres (PHCCs) in Riyadh city, out of which 18 were randomly (https://www.random.org/) selected from the five administrative regions of Riyadh. In addition to PHCCs, we approached five government institutions (technical institutes, college/university and social organizations) to enrol eligible male participants (because males were not able to attend PHCCs as most of them were at work day time).

\section{Study participants}

Saudi adults between 30 and 75 years of age who were permanent residents of Riyadh city were eligible to participate in the WISHES study. Non-Saudis, pregnant women and those with cognitive impairment were not included in the study.

Initially, 3100 adults (1000 males and 2100 females) were invited to participate in the study. Among these adults, 975 males and 2038 females fulfilled the eligibility 
criteria and gave informed and signed consent. However, surveys from 17 of these individuals were discarded due to incomplete blood report/interviews; therefore, 2997 participants (968 males and 2029 females) were finally included in the analysis. The study protocol was approved by the Institutional Review Board (IRB), King Saud University (E-12-658) and the Institutional Review Board of the Ministry of Health, Dammam (IRB ID MOH0151).

\section{Data collection tools}

A questionnaire was developed that comprised a detailed socio-demographic profile, past and current medical history, family history, smoking history and reproductive history (for females only). A copy of the questionnaire specific to this manuscript is attached as "Additional file 1". A team of five females and two male phlebotomists/ data collectors who were well-versed in the Arabic and English languages were rigorously trained by the researchers to conduct the interviews. A pilot study was conducted on a sample of 50 participants to pre-test the questionnaire and assess the feasibility for conducting the study.

\section{Anthropometric and blood pressure measurements}

The anthropometric indices included weight, which was measured with an electronic scale (Secca 220-Hamburg, Germany, 2009), and height, which was measured using the standard method with a stadiometer [31]. Both, weight and height were used to calculate body mass index (BMI) as weight in $\mathrm{kg}$ divided by height in meters squared. Waist circumference (WC) was measured using a measuring tape at the mid-point between the lowest rib and top of the hip bone (iliac crest) [32]. Central obesity for the males and the females was defined as waist circumference of $>90$ and $>80 \mathrm{cms}$, and high central obesity as $>102$ and $>88 \mathrm{cms}$, respectively (WHO, 2008). Two blood pressure readings were taken using the oscillometric method with the participant in an upright position, according to the instruction manual (Omron-5 Series_TM Blood Pressure Monitor Model BP742-China 2010). The average of both readings was computed.

\section{Physical activity}

We used the validated International Physical Activity questionnaire (IPAQ, short form) [33]. The items in the short IPAQ form are structured to provide separate scores for walking, moderate-intensity and vigorous-intensity activity. MET minutes/week (multiples of the resting metabolic rate) were calculated by multiplying the duration of PA (in minutes) with the number of days (per week) and further multiplying with pre-assigned metabolic values of 2.2, 4.0 and 8.0 for walking, moderate-intensity and vigorous-intensity activities, respectively [34]. Continuous scores were converted into the low, moderate and high physical activity categories according to the scoring guidelines [34]. Sitting time, which was considered an indicator of time spent in sedentary activity, was calculated as a continuous variable based on the average time spent sitting on a particular week day (both at work or at home).

\section{Framingham risk scores for CVD}

The FRS covers the full spectrum of CVD, including coronary heart disease, peripheral vascular disease, stroke and heart failure [35]. The online FRS calculator is user-friendly and free of cost [36]. The online calculation requires information on the age, gender, systolic blood pressure (at the time of the interview), treatment for hypertension (yes/no), diabetes (yes/no), smoking (yes/no), total blood cholesterol and high-density lipoprotein (HDL) levels for each participant. The summation of these variables resulted in a continuous score for each participant using the FRS online calculator. These scores were further categorized as follows: individuals with low scores $(<10)$ were considered to have $<10 \%$ risk; those with intermediate scores (between 10 and 20) were considered to have 11 to $20 \%$ risk; and those with high scores $(>20)$ were considered to have $>20 \%$ risk of developing CVD in the next ten years [35].

\section{Blood collection procedures}

A random sample of non-fasting $10 \mathrm{~mL}$ of venous blood was collected using a needle of 22 or 23 gauge along with a sample adaptor to fill the test tube $(5 \mathrm{~mL}$ in a yellow-capped test tube for basic biochemistry [cholesterol, high density lipo-protein (HDL)]. The test tubes were placed into a labelled plastic bag, which was placed in a cold box lined with ice packs. Then, the samples were transferred to the laboratory of King Khaled University Hospital (KKUH) at the end of the working day and stored at a temperature of 2 to 8 degrees Celsius until analysis.

\section{Measurement of lipids}

Serum levels of total cholesterol and HDL-cholesterol were measured with a fully automated analyser (Siemens Dimension RxL, Germany) using enzymatic methods. The intra-assay and inter-assay coefficients of variation were 0.84 and 1.30 , respectively, for total cholesterol, and 1.9 and 2.1 for HDL-cholesterol.

\section{Statistical analysis}

The data were analysed using the Statistical Package for the Social Sciences computer software package (IBM SPSS statistics version 21.0). The mean values and standard deviations were computed for the continuous variables, and frequency and proportions were calculated for the categorical variables. The Student's t-test for independent samples and the Chi-squared test were used to analyse the differences between FRS and the associated 
variables in relation to gender. The Pearson's correlation coefficient ( $r$ ) was calculated between continuous variables. The outcome variable (FRS) was evaluated as a dichotomous variable for which participants with an intermediate or high FRS $(\geq 10)$ were considered "at risk" and coded as (1), vs. low risk (FRS $<10)$, which was coded as (0). The multivariable logistic regression analyses were used to estimate the association between FRS (outcome variable) and sedentary lifestyle (exposure variable), including physical activity, sitting time, and waist circumference. The model was adjusted for education level and type of housing (proxy indicator for socioeconomic status). Vigorous and moderate physical activity were summed to create one variable (coded as 1) vs. low physical activity (coded as 0 ). Continuous sitting time of the participants was converted to hours and categorized according to average sitting time into a dichotomous variable coded as $0=\leq 6 \mathrm{~h}$ and $1=>6 \mathrm{~h}$ [37]. The level of statistical significance was set as $p<0.05$. All plausible interactions were checked before the development of the model. The Hosmer Lemeshow goodness of fit test was used to assess the model fit.

\section{Results}

The number of Saudi male participants with intermediate-to-high FRS scores $(\geq 10)$ was almost twice that of females (males $33 \%$ vs $17 \%$ ). Similarly, the mean $( \pm \mathrm{SD})$ FRS for the males were higher as compared to females $(9.5( \pm 8.6)$ vs $5.5( \pm 6.5) p<0.001)$. Comparisons between age and gender revealed that a significant proportion of males between ages 30-50 years had FRS $\geq 10$. Whereas, for females, a significant proportion between 51 and 75 years had FRS $\geq 10$ (Table 1 ).
The mean age between males and females was not significantly different [43.1 $( \pm 11.7)$ vs $43.8( \pm 10.9), p=0.07)]$. Males exhibited a higher mean waist circumference compared to females $[96.2(( \pm 14.2)$ vs $92.7( \pm 14.0)$ $(p<0.001)]$, whereas the mean body mass index for females was higher than for males $[29.6( \pm 6.4)$ vs $31.4( \pm 6.5)$ $(\mathrm{p}<0.001)]$. Significant correlation was observed between BMI and waist circumference $(r=0.4, p<0.001)$ (results not shown). Males exhibited significantly lower mean HDL levels compared to females (Table 2). The age and gender comparison revealed that in the male participants, risk factors such as diabetes mellitus, hypertension, hypertriglyceridemia low HDL, smoking were more frequently reported/detected in the age groups of 30 to 50 years; whereas in females, a significant increase in these risk factors was observed in the age group of 51 to 60 years old (results not shown). Similar to above factors, physical activity and sitting time showed similar trend. The highest percentage of participants with low physical activity and prolonged sitting time belonged to 30-40 years age category, whereas after 50 years of age, more females reported sedentary life style compared to the males (Fig. 1).

Male participants reported higher levels of education compared to female participants. The majority of participants were married, and the average number of children reported by married women was $5.2( \pm 2.9)$. Approximately one-quarter of the currently married females were using some form of contraception, with oral pills being the most commonly reported method $(n=343)$. Approximately $18 \%(n=542)$ of women had reached menopause (results not shown).

The average sitting time for a single week day was 360 $( \pm 218)$ minutes (equal to $6.0 \mathrm{~h}$ ); however, longer

Table 1 Framingham risk scores in Saudi males and females, by age category $(n=2997)$

\begin{tabular}{|c|c|c|c|c|c|}
\hline \multirow{2}{*}{$\begin{array}{l}\text { Framingham } \\
\text { Risk scores }\end{array}$} & \multicolumn{4}{|c|}{ Age in years ${ }^{b}$} & \multirow{2}{*}{$\begin{array}{l}\text { Total }=2997^{\mathrm{a}} \\
\text { Males }=968 \\
\text { Females }=2029\end{array}$} \\
\hline & $30-40$ & $41-50$ & $51-60$ & $61-75$ years & \\
\hline \multicolumn{6}{|c|}{ Low risk $(\text { score }<10)^{1}$} \\
\hline Males & $450(69.4)$ & $164(25.3)$ & $31(4.8)$ & $3(0.5)$ & $648(66.9)$ \\
\hline Females & $929(55.2)$ & $513(30.5)$ & $209(12.4)$ & $32(1.9)$ & $1683(82.9)$ \\
\hline Total & $1379(59.2)$ & $677(29.0)$ & $240(10.3)$ & $35(1.5)$ & $2331(77.8)$ \\
\hline \multicolumn{6}{|c|}{ Intermediate Risk (score $\geq 10-20)^{1}$} \\
\hline Males & $19(10.4)$ & $82(44.8)$ & $62(33.9)$ & $20(10.9)$ & $183(18.9)$ \\
\hline Females & $2(0.8)$ & $55(23.2)$ & $123(51.9)$ & $57(24.1)$ & $237(11.7)$ \\
\hline Total & $21(1.5)$ & $137(32.6)$ & $185(44.0)$ & $77(18.3)$ & $420(14.0)$ \\
\hline \multicolumn{6}{|c|}{ High Risk (score $>20)^{2}$} \\
\hline Males & $4(2.9)$ & $26(19.0)$ & $45(32.8)$ & $62(45.3)$ & $137(14.2)$ \\
\hline Females & $1(0.9)$ & $5(4.6)$ & $43(39.4)$ & $60(55.0)$ & $109(5.4)$ \\
\hline Total & $5(2.0)$ & $31(12.6)$ & $88(35.8)$ & $122(49.6)$ & $246(8.2)$ \\
\hline
\end{tabular}

${ }^{1} p$ value $<0.001 ;{ }^{2} p$ value $<0.01$

${ }^{\mathrm{a} C o l u m n}$ percentage; ${ }^{\mathrm{b}}$ Row percentage 
Table 2 Descriptive characteristics under Framingham risk scores for Saudi males and females in Riyadh, Saudi Arabia, N= 2997

\begin{tabular}{|c|c|c|c|}
\hline Variables & $\begin{array}{l}\text { Males } \\
\text { Mean }( \pm S D)\end{array}$ & $\begin{array}{l}\text { Females } \\
\text { Mean }( \pm S D)\end{array}$ & $P$ value \\
\hline Framingham Risk scores & $9.4( \pm 8.6)$ & $5.4( \pm 6.5)$ & $<0.001$ \\
\hline Age (in years) & $43.1( \pm 11.7)$ & $43.8( \pm 10.9)$ & 0.07 \\
\hline Systolic Blood pressure $(\mathrm{mmHg})$ & $124( \pm 15.2)$ & $120( \pm 18.0)$ & $<0.001$ \\
\hline Mean Cholesterol levels (mg/dL) & $194( \pm 41.5)$ & 195( \pm 37.3$)$ & 0.2 \\
\hline Mean HDL levels (mg/dL) & $43.1( \pm 10.8)$ & $54.1( \pm 13.8)$ & $<0.001$ \\
\hline \multicolumn{4}{|l|}{ Age (in years category) (n\%) } \\
\hline $30-40$ & $473(48.9)$ & $932(45.9)$ & \multirow[t]{4}{*}{0.02} \\
\hline $41-50$ & $272(28.1)$ & $573(28.2)$ & \\
\hline $51-60$ & $138(14.3)$ & $375(18.5)$ & \\
\hline $61-75$ & $85(8.8)$ & $149(7.3)$ & \\
\hline \multicolumn{4}{|l|}{ Systolic Blood Pressure(mmHg) } \\
\hline$\leq 140 \mathrm{mmHg}$ & $824(85.1)$ & $1753(86.4)$ & \multirow[t]{2}{*}{0.3} \\
\hline$>140 \mathrm{mmHg}$ & $144(14.9)$ & $276(13.6)$ & \\
\hline \multicolumn{4}{|l|}{ Treatment for Hypertension } \\
\hline Yes & 99 (10.2) & $344(17.0)$ & \multirow[t]{2}{*}{0.6} \\
\hline No & $869(89.8)$ & $1685(83.0)$ & \\
\hline \multicolumn{4}{|l|}{ Diabetes Mellitus } \\
\hline Yes & $164(16.9)$ & $442(21.8)$ & \multirow[t]{2}{*}{0.02} \\
\hline No & $804(83.1)$ & $1587(78.2)$ & \\
\hline \multicolumn{4}{|l|}{ Smoking } \\
\hline Yes & $268(27.7)$ & $44(2.2)$ & \multirow[t]{2}{*}{$<0.001$} \\
\hline No & $700(72.3)$ & $1985(97.8)$ & \\
\hline \multicolumn{4}{|l|}{ Blood Cholesterol level (mg/dL) ${ }^{a}$} \\
\hline Normal & $577(59.6)$ & $1180(58.2)$ & \multirow[t]{2}{*}{0.4} \\
\hline Raised & $391(40.4)$ & $849(41.8)$ & \\
\hline \multicolumn{4}{|l|}{ High Density Lipoprotein $(\mathrm{mg} / \mathrm{dL})^{\mathrm{b}}$} \\
\hline Normal & $564(58.3)$ & $1744(86.0)$ & \multirow[t]{2}{*}{$<0.001$} \\
\hline Abnormal & $404(41.7)$ & $285(14.0)$ & \\
\hline
\end{tabular}

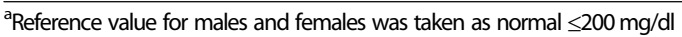
and raised $>200 \mathrm{mg} / \mathrm{dl}$

${ }^{\mathrm{b}}$ Reference value for males and females was taken as normal $\geq 40 \mathrm{mg} / \mathrm{dl}$ and abnormal $<40 \mathrm{mg} / \mathrm{dl}$

durations were reported by the males compared to females $(8.0 \mathrm{~h}$ vs. $5.0 \mathrm{~h}$, respectively, $p<0.01)$. A weak, but significant negative Pearson's correlation coefficient value was detected between physical activity and sitting time $(r=-0.16, p<0.001)$. Bivariate analysis revealed that participants were more likely to have an FRS $\geq 10$ if they were married vs single; if they had an intermediate level of education vs graduate or higher level; or if they were a house wife or worked as a doctor/engineer or were retired vs working as teacher/secretary (Table 3). Family medical history was not shown to be significantly associated with FRS in this study.
The multivariable logistic regression model, after adjusting for education level and housing type, revealed that the following factors were associated with FRS: low physical activity (aOR \& 95\% CI for males 2.91 (1.45, $5.80)$ and females 1.38 (1.06, 1.81); prolonged sitting time (aOR \&95\% CI for females 1.58 (1.20, 2.07), and high central obesity (aOR\& 95\% CI for males $2.38(1.67,3.41)$ and females $3.35(1.92,5.87)$. In the males, sitting time $>6 \mathrm{~h}$ was marginally associated with FRS (aOR $1.36(0.98,1.90)$. Living in an apartment was protective against a high FRS for males (aOR $0.35,95 \%$, CI $(0.17,0.71)$, whereas living in villas, as opposed to Arabic-style housing, was associated with FRS in the females (aOR $2.13(1.41,3.24)$. Participants with a low level of education (intermediate and below) were more likely to have a high FRS (aOR for males 3.49 (2.52, 4.82), females $6.23(4.31,8.99)$, compared to those with a university-level education and higher (Table 4).

\section{Discussion}

The overall ten-year high/intermediate CVD risk (FRS $\geq 10$ ) tended to increase with increasing age in both males and females, but this risk was higher in males compared with females (33.1\% vs $17.1 \%)$. Previous research determined that men have a greater CVD risk compared with pre-menopausal women, but the risk is similar for post-menopausal women and men [38]. Similar trend was evident in our results, as significant proportion of males had CVD risk in the age category of 30 to 50 years, whereas females were in greater proportion after crossing the age of 50 years. Several explanations related to life, style including physical activity, smoking prevalence, menopause and cholesterol metabolism may help in explaining this variation [39].

The Saudi population has a high prevalence of diabetes mellitus (DM), hypertension (HTN), smoking, hyperlipidaemia, physical inactivity, overweight and obesity [40, 41]. The previous literature is in agreement with our findings, which demonstrated that although the CVD risk tended to be similar in men and women, the individual risk factors differed; for example, smoking is more frequent in men, diabetes mellitus and high-density lipoprotein (HDL) levels are lower in men compared with women, and hypertension is reported to be greater in women aged 65 years or more [42-44].

Apart from age, sex, and family history, most of the above mentioned risk factors are modifiable, and individuals with modifiable risk factors require regular check-ups. It is practical to estimate CVD risk in asymptomatic individuals, using the resulting data to promote knowledge, awareness and as motivation for adopting healthy lifestyles for therapeutic changes [38]. A study from the USA demonstrated a decline in FRS over a 


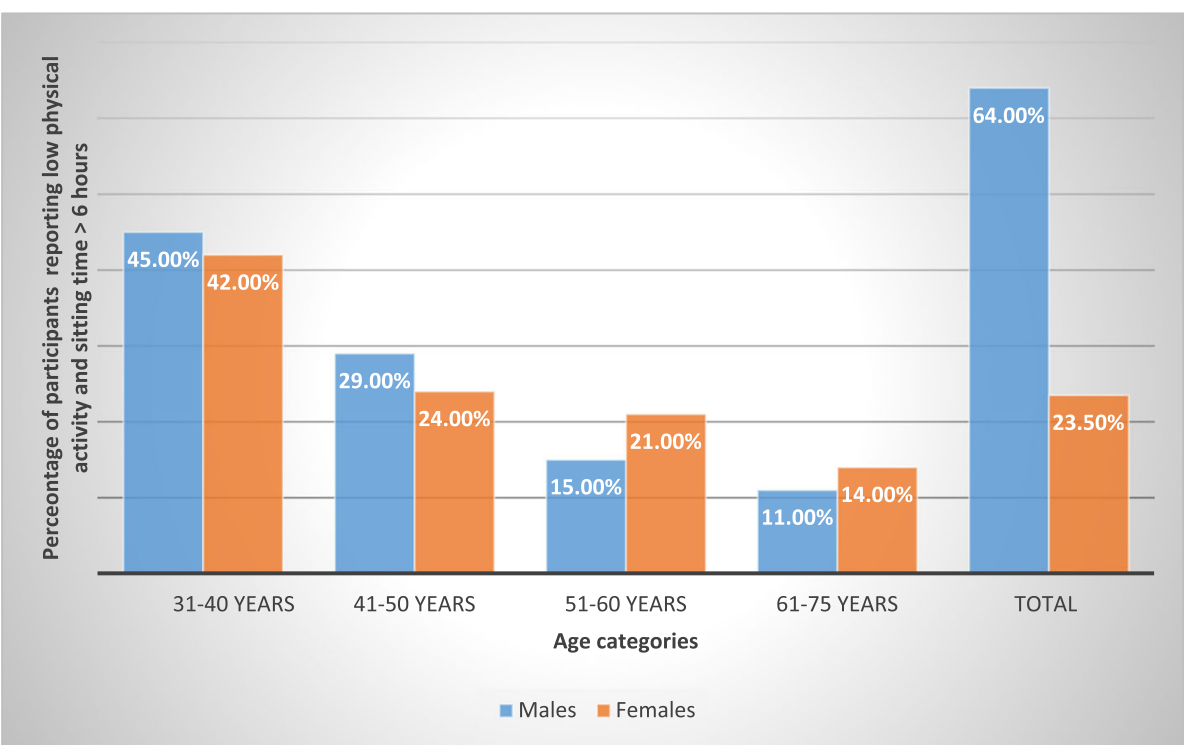

Fig. 1 Percentage of males and females reporting low physical activity \& sitting time of $>6$ h by age categories in Riyadh, Saudi Arabia

period of 15 years among a population undergoing percutaneous intervention and demonstrated a major reduction in the lipid profile and hypertension, whereas risk factors related to body mass index and age increased in the study population [45]. However, even in individuals with moderate or low FRS scores, medical conditions like stroke or acute MI cannot be ruled out, hence it is better to screen them by utilising multiple techniques, in addition to the FRS [45].

European cohort studies showed that FRS underestimated CVD risk in deprived populations and overestimated CVD risk in high risk populations [46, 47]. The NHANES survey data demonstrated a reduction in CVD risk in the US population from 1976 to 1980 to 1988-1994 but less of a reduction from 1988 to 1994 to 1999-2004, particularly in women and middle-aged people [48]. Over the period of thirty years in the USA, changes in risk factors occurred at different rates; and one important contributing factor was an increase in the frequency of obesity over time [48]. Our study revealed that waist circumference, defined as central obesity, was associated with a high FRS in both males and females. The high central obesity in the Saudi population shown in our study implies that this risk is already present in males and females, and any decline in FRS will require tremendous efforts.

Sedentary behaviour and prolonged sitting time are consequences of the social and environmental determinants of urban living; this risk factor awaits interventional investigations to be translated into recommendations [49-51]. A crossover trial demonstrated improved glucose metabolism through brief interruptions of short bouts of light and moderate activity during sitting time [52]. A study from Saudi Arabia conducted in women $\geq 30$ years likewise reported a relationship between increased household activities and strenuous exercise with a reduction in CVD risk [50]. Overall, physical inactivity is high in Saudi Arabia $(66.6 \%)$, with $87.9 \%$ of leisure time spent in physical inactivity [53], especially in elderly, divorced and widowed persons; however, health education has resulted in improvements in lifestyle and physical activity [54]. Our study revealed that a greater percentage of males, compared to females, exhibited a sedentary lifestyle, including low physical activity and prolonged sitting time [ $8 \mathrm{~h}$ vs 5.5 h]. The prospective follow up of $>11$ years of a European cohort of men and women revealed changes in the FRS of the participants and demonstrated that those with sedentary lifestyle had the highest risk of CVD [55]. Our findings could potentially be used to devise lifestyle adaptations for improving physical activity, reducing sitting time and addressing adult obesity; such lifestyle changes have been reported to reduce the risk for coronary heart disease (CHD) by $50 \%$ [56].

The FRS scores obtained in our study are compatible with local reports of the Saudi population [57] and international populations [58]. The FRS was twice as high for individuals with a first-degree relative who had CVD before the age of 55 in men, and 65 in women [58]. The Saudi study was conducted on 4932 men and women greater than 20 years of age without coronary heart disease, and the results showed that diabetes, dyslipidaemia, and hypertension increased with age [57]. It is evident that the Saudi population has a substantial burden of risk factors, and assessing these risks based upon FRS score in the younger population may not adequately identify individuals who require therapeutic and non-therapeutic interventions [59]. 
Table 3 Uni-variable logistic regression analysis between sociodemographic, lifestyle, family history and anthropometric measurements with FRS in Saudi males and females in Riyadh, Saudi Arabia

\begin{tabular}{|c|c|c|c|c|c|c|}
\hline \multirow[t]{2}{*}{ Variables } & \multicolumn{3}{|l|}{ Males $(N=968)$} & \multicolumn{3}{|c|}{ Females $(N=2029)$} \\
\hline & FRS $\geq 10(n=320)$ & $\begin{array}{l}\text { FRS }<10 \\
(n=648)\end{array}$ & $\begin{array}{l}\text { Unadjusted odds } \\
\text { ratio \& } 95 \% \mathrm{Cl}\end{array}$ & $\begin{array}{l}\text { FRS } \geq 10 \\
(n=346)\end{array}$ & $\begin{array}{l}\text { FRS }<10 \\
(n=1683)\end{array}$ & $\begin{array}{l}\text { Unadjusted odds } \\
\text { ratio \& } 95 \% \mathrm{Cl}\end{array}$ \\
\hline \multicolumn{7}{|l|}{ Sociodemographic profile } \\
\hline \multicolumn{7}{|l|}{ Marital status } \\
\hline Single & $8(2.5)$ & $94(14.5)$ & 1.0 & $4(1.2)$ & $142(8.4)$ & 1.0 \\
\hline Married (include widow) & $312(97.5)$ & $554(85.5)$ & $6.6(3.1,13.8)$ & $342(98.8)$ & 1541(91.6) & $7.8(2.8,21.4)$ \\
\hline \multicolumn{7}{|l|}{ Participants Education } \\
\hline Graduation and above & $181(56.6)$ & $533(82.3)$ & 1.0 & $39(11.3)$ & $837(49.7)$ & 1.0 \\
\hline Intermediate and below & 139(43.4) & $115(17.7)$ & $3.5(2.6,4.8)$ & $307(88.7)$ & $846(50.3)$ & $7.7(5.5,11.0)$ \\
\hline \multicolumn{7}{|l|}{ Spouse's education } \\
\hline \multicolumn{7}{|l|}{$(M=866, F=1883)$} \\
\hline Graduation \& above & $113(36.2)$ & $361(65.2)$ & 1.0 & 77 (22.5) & $684(44.4)$ & 1.0 \\
\hline Intermediate and below & $199(63.8)$ & 193(34.8) & $3.2(2.4,4.4)$ & $265(77.5)$ & $857(55.6)$ & $2.7(2.0,3.6)$ \\
\hline \multicolumn{7}{|l|}{ Participants occupation } \\
\hline Teacher/secretary/ etc. ${ }^{c}$ & $152(47.5)$ & $471(72.7)$ & 1.0 & $51(14.7)$ & $717(42.6)$ & 1.0 \\
\hline Military service & $32(10.0)$ & $82(12.7)$ & $1.2(0.7,1.8)$ & - & - & - \\
\hline Housewife & - & - & - & $266(76.9)$ & $783(46.5)$ & $4.7(3.4,6.5)$ \\
\hline Doctor/Engineer/lawyer ${ }^{\mathrm{b}}$ & $40(12.5)$ & $69(10.6)$ & $1.8(1.2,2.7)$ & $11(3.2)$ & $39(2.3)$ & $3.9(1.9,8.2)$ \\
\hline Unemployed & $9(2.8)$ & $18(2.8)$ & $1.5(0.6,3.5)$ & $5(1.4)$ & $98(5.8)$ & $0.7(0.3,1.8)$ \\
\hline Retired & $87(27.2)$ & $8(1.2)$ & $33.6(15.9,71.3)$ & $13(3.8)$ & $46(2.7)$ & $3.9(2.0,7.8)$ \\
\hline \multicolumn{7}{|l|}{$\begin{array}{l}\text { Spouse's occupation } \\
(\mathrm{M}=866, \mathrm{~F}=1883)\end{array}$} \\
\hline Skilled professions ${ }^{c}$ & $78(25.0)$ & $191(34.5)$ & 1.0 & $59(17.3)$ & $559(36.3)$ & 1.0 \\
\hline Military service & - & - & & $24(7.0)$ & $250(16.2)$ & $4.6(3.3,6.4)$ \\
\hline Housewife & $215(68.9)$ & $303(54.7)$ & $1.7(1.3,2.4)$ & - & - & - \\
\hline Doctors/Engineer/lawyer ${ }^{b}$ & $6(1.9)$ & $27(4.9)$ & $0.5(0.2,1.4)$ & $87(25.4)$ & $314(20.4)$ & $3.3(1.5,7.2)$ \\
\hline Unskilled/ unemployed & $2(0.6)$ & $28(5.1)$ & $0.1(0.04,0.7)$ & $9(2.6)$ & $68(4.4)$ & $0.7(0.2,2.0)$ \\
\hline Retired & $11(3.5)$ & $5(0.9)$ & $5.4(1.8,16.0)$ & $163(47.7)$ & $350(22.7)$ & $4.4(2.0,9.2)$ \\
\hline \multicolumn{7}{|l|}{ Monthly Income level } \\
\hline \multicolumn{7}{|l|}{$(S A R)^{d}$} \\
\hline \multicolumn{7}{|l|}{$(M=943, F=1718)$} \\
\hline$\leq 10,000$ & $111(35.9)$ & $209(33.0)$ & 1.0 & 159(63.9) & $827(56.3)$ & 1.0 \\
\hline$>10,000$ & $198(64.1)$ & $425(67.0)$ & $0.9(0.6,1.2)$ & $90(36.1)$ & $642(43.79)$ & $0.7(0.5,1.0)$ \\
\hline \multicolumn{7}{|l|}{ Type of housing $^{e}$} \\
\hline Arabic style house & $16(5.0)$ & $35(5.4)$ & 1.0 & $32(9.2)$ & $241(14.3)$ & 1.0 \\
\hline Apartment & $55(17.2)$ & $286(44.1)$ & $0.4(0.2,0.8)$ & $37(10.7)$ & $437(26.0)$ & $0.6(0.4,1.0)$ \\
\hline Villa & 249(77.8) & $327(50.5)$ & $1.7(0.9,3.1)$ & $277(80.1)$ & 1005(59.7) & $2.1(1.4,3.1)$ \\
\hline \multicolumn{7}{|l|}{ Ownership of house } \\
\hline Company owned & $5(1.6)$ & $17(2.6)$ & 1.0 & $10(2.9)$ & $73(4.3)$ & 1.0 \\
\hline Rented & $75(23.6)$ & $273(42.2)$ & $0.9(0.3,2.6)$ & $50(14.5)$ & $449(26.7)$ & $0.8(0.4,1.6)$ \\
\hline Self-owned & $238(74.8)$ & $357(55.2)$ & $2.2(0.8,6.2)$ & $286(82.7)$ & $1158(68.9)$ & $1.8(0.9,3.5)$ \\
\hline \multicolumn{7}{|c|}{ Anthropometric measurements \& Physical activity } \\
\hline \multicolumn{7}{|l|}{ Body Mass Index $\left(\mathrm{kg} / \mathrm{m}^{2}\right)^{\mathrm{f}}$} \\
\hline Normal $(<25)$ & $48(15.0)$ & $155(23.9)$ & 1.0 & $24(6.9)$ & $266(15.8)$ & 1.0 \\
\hline
\end{tabular}


Table 3 Uni-variable logistic regression analysis between sociodemographic, lifestyle, family history and anthropometric measurements with FRS in Saudi males and females in Riyadh, Saudi Arabia (Continued)

\begin{tabular}{|c|c|c|c|c|c|c|}
\hline \multirow[t]{2}{*}{ Variables } & \multicolumn{3}{|l|}{ Males $(N=968)$} & \multicolumn{3}{|c|}{ Females $(N=2029)$} \\
\hline & FRS $\geq 10(n=320)$ & $\begin{array}{l}\text { FRS }<10 \\
(n=648)\end{array}$ & $\begin{array}{l}\text { Unadjusted odds } \\
\text { ratio \& 95\% Cl }\end{array}$ & $\begin{array}{l}\text { FRS } \geq 10 \\
(n=346)\end{array}$ & $\begin{array}{l}\text { FRS }<10 \\
(n=1683)\end{array}$ & $\begin{array}{l}\text { Unadjusted odds } \\
\text { ratio \& 95\% Cl }\end{array}$ \\
\hline Overweight $(\geq 25$ to $<30)$ & $120(37.5)$ & $244(37.7)$ & $1.6(1.1,2.3)$ & $81(23.4)$ & $508(30.2)$ & $1.7(1.1,2.8)$ \\
\hline Obese $(\geq 30)$ & $152(47.5)$ & $249(38.4)$ & $1.9(1.3,2.8)$ & $241(69.7)$ & $909(54.0)$ & $2.9(1.8,4.5)$ \\
\hline \multicolumn{7}{|l|}{$\begin{array}{l}\text { Waist Circumference } \\
\text { (in } \mathrm{cms})^{9}\end{array}$} \\
\hline Normal & $114(35.6)$ & $337(52.0)$ & 1.0 & $18(5.2)$ & $365(21.7)$ & 1.0 \\
\hline Central obesity & $82(25.6)$ & $149(23.0)$ & $1.6(1.1,2.3)$ & $35(10.1)$ & $359(21.3)$ & $1.9(1.1,3.5)$ \\
\hline High central obesity & $124(38.8)$ & $162(25.0)$ & $2.2(1.6,3.1)$ & $293(84.7)$ & $959(57.0)$ & $6.1(3.7,10.1)$ \\
\hline \multicolumn{7}{|l|}{ Physical Activity ${ }^{h}$} \\
\hline High \& Moderate & $11(3.4)$ & $77(11.9)$ & 1.0 & $127(36.7)$ & $782(46.5)$ & 1.0 \\
\hline Low & 309 (96.6) & $571(88.1)$ & $3.7(1.9,7.2)$ & $219(63.3)$ & $901(53.5)$ & $1.5(1.1,1.8)$ \\
\hline \multicolumn{7}{|l|}{ Sitting time/week day } \\
\hline \multicolumn{7}{|l|}{$(M=950 ; F=2008)$} \\
\hline$\leq 6.0 \mathrm{~h}$ & $83(26.3)$ & $209(33.0)$ & 1.0 & $201(59.1)$ & 1178 (70.6) & 1.0 \\
\hline$>6.0 \mathrm{~h}$ & $233(73.7)$ & $425(67.0)$ & $1.4(1.0,1.9)$ & $139(40.9)$ & $490(29.4)$ & $1.7(1.3,2.1)$ \\
\hline \multicolumn{7}{|l|}{ Family history } \\
\hline \multicolumn{7}{|l|}{ Family history for Hypertension } \\
\hline No & $194(60.6)$ & $394(60.8)$ & 1.0 & $148(42.8)$ & $727(43.2)$ & 1.0 \\
\hline Yes & $126(39.4)$ & $254(39.2)$ & $1.0(0.7,1.3)$ & $198(57.2)$ & $956(56.8)$ & $1.0(0.8,1.2)$ \\
\hline \multicolumn{7}{|c|}{ Family history for Diabetes Mellitus $(\mathrm{M}=953, \mathrm{~F}=2022)$} \\
\hline No & $167(52.8)$ & $336(52.7)$ & 1.0 & $108(31.3)$ & $634(37.8)$ & 1.0 \\
\hline Yes & $149(47.2)$ & $301(47.3)$ & $1.0(0.8,1.3)$ & $237(68.7)$ & $1043(62.2)$ & $1.3(1.0,1.7)$ \\
\hline \multicolumn{7}{|l|}{ Family history for CVD } \\
\hline No & $276(86.3)$ & $555(85.6)$ & 1.0 & $279(80.6)$ & $1382(82.1)$ & 1.0 \\
\hline Yes & $44(13.8)$ & $93(14.4)$ & $0.9(0.6,1.4)$ & $67(19.4)$ & $301(17.9)$ & $1.1(0.8,1.5)$ \\
\hline \multicolumn{7}{|l|}{ Age of family members with CVD } \\
\hline No family history & $276(86.3)$ & $555(85.6)$ & 1.0 & $279(80.6)$ & $1382(82.1)$ & 1.0 \\
\hline Father/ brother age 45 years & $20(6.3)$ & $56(8.6)$ & $0.7(0.4,1.2)$ & $29(8.4)$ & $148(8.8)$ & $0.9(0.6,1.5)$ \\
\hline Mother/sister age of 55 year & $24(7.5)$ & $37(5.7)$ & $1.3(0.7,2.2)$ & $38(11.0)$ & $153(9.1)$ & $1.2(0.8,1.8)$ \\
\hline
\end{tabular}

aincludes currently married, divorced and separated

${ }^{b}$ includes businesspersons, finance manager

'Teacher, secretary, health and allied staff, technicians, etc

eArabic type house is a traditional type of house where several families belonging to the same tribe reside

${ }^{\mathrm{f}} \mathrm{BMI}$ of $18.5-24.9$ as normal weight, $25.0-29.9$ as overweight and $\geq 30$ as obese

${ }^{9} \mathrm{High} /$ vigorous physical activity defined as at least 3 days of activity achieving a minimum total physical activity of at least 1500 MET-minutes/week and moderate as " 5 or more days of moderate-intensity activity and/or walking of at least $30 \mathrm{~min}$ per day" and low activity those not included in high or moderate activity

hWaist circumference Normal (Females $<80 \mathrm{cms}$, Males $<90 \mathrm{cms}$; Central obesity (Females $>80<88 \mathrm{cms}$, Males $>90<102 \mathrm{cms}$ ); High central obesity

(Females $>88 \mathrm{cms}$, Males $>102 \mathrm{cms}$ )

'sitting time cut-off 6.0 is based on the average sitting time in Saudi population on any weekday

A study from a Scandinavian country reported that apartment living was associated with physical inactivity [60]. However, we obtained contradictory findings wherein residing in an apartment was shown to be protective for males, whereas residing in villas increased the likelihood for females to have a higher FRS. Such diverse findings may be due to operating socio-demographic and environmental factors, which may have undervalued the prevailing risk and require further evaluation. Environmental conditions have been hypothesized to predispose individuals to risky behaviour, and recommendations have been made for testing this hypothesis [48].

Our study has several strengths. First, it was a community based study, conducted in the primary care setting and may accurately represent the Riyadh city population. The FRS has been used in previous studies from Saudi 
Table 4 Multivariable logistic regression models** for association of FRS (> 10) with life style factors in Saudi male and females in Riyadh, Saudi Arabia 2014-2015

\begin{tabular}{|c|c|c|}
\hline Variables & $\begin{array}{l}\text { Males } \\
\text { Odds Ratio }(95 \% \mathrm{Cl})\end{array}$ & $\begin{array}{l}\text { Females } \\
\text { Odds Ratio }(95 \% \mathrm{Cl})\end{array}$ \\
\hline \multicolumn{3}{|l|}{ Physical Activity } \\
\hline $\begin{array}{l}\text { Moderate/high } \\
\text { physical activity }^{\text {a }}\end{array}$ & 1.0 & 1.0 \\
\hline Low physical activity ${ }^{b}$ & $2.91(1.45,5.80)^{*}$ & $1.38(1.06,1.81)^{*}$ \\
\hline \multicolumn{3}{|l|}{ Sitting time/week day } \\
\hline Sitting time $\leq 6.0 \mathrm{~h}$ & 1.0 & 1.0 \\
\hline Sitting time $>6.0 \mathrm{~h}$ & $1.36(0.98,1.90)$ & $1.58(1.20,2.07)^{*}$ \\
\hline \multicolumn{3}{|l|}{ Waist Circumference $^{c}$} \\
\hline Normal & 1.0 & 1.0 \\
\hline Central obesity & $1.88(1.29,2.72)^{*}$ & $1.58(0.83,2.99)$ \\
\hline High central obesity & $2.38(1.67,3.41)^{*}$ & $3.35(1.92,5.87)^{*}$ \\
\hline \multicolumn{3}{|l|}{ Type of housing } \\
\hline Arabic style house $^{d}$ & 1.0 & 1.0 \\
\hline Apartment & $0.35(0.17,0.71)^{*}$ & $0.77(0.45,1.29)$ \\
\hline Villa & $1.46(0.75,2.83)$ & $2.13(1.41,3.24)^{*}$ \\
\hline \multicolumn{3}{|l|}{ Participants Education } \\
\hline Graduation and above & 1.0 & 1.0 \\
\hline Intermediate and below & $3.49(2.52,4.82)^{*}$ & $6.23(4.31,8.99)^{*}$ \\
\hline
\end{tabular}

**Models were adjusted for education level and housing type

*values indicate statistically significant with $p<0.05$

ahigh/vigorous physical activity defined as "at least 3 days of activity achieving

a minimum total physical activity of at least 1500 MET-minutes/week" and moderate as " 5 or more days of moderate-intensity activity and/or walking of at least 30 min per day" and low activity those not included in high or moderate activity

${ }^{b}$ sitting time cut-off 6.0 was based on the average sitting time in Saudi population on any week day

'Waist circumference was defined as Normal (Females $<80 \mathrm{cms}$, Males $<90 \mathrm{cms}$; Central obesity (Females $>80<88 \mathrm{cms}$, Males $>90<102 \mathrm{cms}$ ); High central obesity (Females $>88 \mathrm{cms}$, Males $>102 \mathrm{cms}$ )

${ }^{\mathrm{d}}$ Arabic type house is a traditional type of house where several families belonging to the same tribe reside

Arabia, and the results are comparable to other standard risk scoring methods [61]. Second, our results provide adequate evidence for the risk factors for CVD and preventive applications to target Saudi males and females for primary and secondary prevention of CVD. Third, our study is one of the few studies that uses sitting time as a predictive factor of FRS in Saudi Arabia, along with physical inactivity. Fourth, a large sample size stratified by age and sex provided comparable estimates that are consistent with other reports on similar topics [42, 48].

However, this study also has certain limitations. This was a cross-sectional study; hence, we could not establish a temporal relationship between the risk factors and CVD risk. We cannot rule out the selection bias that may have occurred for males and females approaching PHCC, as they could be individuals with high FRS scores. Hence our OR estimates could be slightly overestimates; however, there could be other possibility that those with much worse FRS may not have come to PHCC. High accessibility is reported for PHCC for maternal and child health but less accessed for non-communicable diseases [62]. Recall and information biases may have played a role in the reporting of sitting time and physical activity, which may have resulted in misclassification and inaccuracy in these data; however, the use of a physical activity assessment tool has been validated and is reported to underestimate, rather than overestimate, CVD risk [63]. In addition, it is possible that we did not adjust for all potentially confounding variables; thus, residual confounding may have resulted.

Selected cohorts of high-risk populations could be studied using culturally tailored interventions on behavioural and other therapeutic interventions along with other novel markers [64, 65]. We used self-reported physical sitting and activity time, which may be inaccurate; however, it has been validated that self-reported physical activity time attenuates the relationship with FRS scores [63]. PHCCs can serve as multipurpose facility, ranging from screening to bringing changes in life style. A recent report by Ministry of Health refers to use PHCC for promotion of PA in Saudi population [66]. FRS scores obtained in a large population need to be followed by specific algorithms at the population and individual level to adequately address the risks with a two-pronged approach - especially in Saudi populations that exhibit abundant risk factors.

\section{Conclusion}

Females beyond the age of 50 were found to have a higher prevalence for CVD risk and associated factors compared to males of the same age groups. Modifiable risk factors, including prolonged sitting time, increased waist circumference and low physical activity in Saudi men and women from Riyadh have strong implications for primary prevention and management services, which can change the risk profile of the Saudi population. Therefore, culturally appropriate interventions need to be designed and tested.

\section{Additional file}

Additional file 1: Women in Saudi Arabia Health Examination Survey. (DOCX 39 kb)

\section{Abbreviations}

ACE: Africa Middle East cardiovascular epidemiological; BMI: Body mass index; CHD: Coronary heart disease; DM: Diabetes mellitus; FRS: Framingham risk scores; GCC: Gulf countries council; HDL: High density lipoprotein; IPAQ: International physical activity questionnaire; KKUH: King Khalid University hospital; KSA: Kingdom of Saudi Arabia; MET: Metabolic energy expenditure; MI: Myocardial infarction; NHANES: National health and nutrition examination survey; PA: Physical activity; PHCC: Primary health care centres; RACE: Registry for acute coronary events; SD: Standard deviation; 
SPSS: Statistical package for social sciences; WC: Waist circumference; WISHES: Women in Saudi Arabia health examination survey

\section{Acknowledgements}

We shall like to thank the Ministry of Health, Saudi Arabia for allowing and facilitating us to conduct this study in the primary health care centres. We also like to acknowledge all the participants for their time and cooperation. We shall like to thank Mr. Bushra Abdul Wahab and Mrs. Maha Younis for providing the logistic support during data collection.

\section{Funding}

This Project was funded by the National Plan for Science, Technology and Innovation (MAARIFAH), King Abdulaziz City for Science and Technology, Kingdom of Saudi Arabia, Award Number (12-MED2687-02). The funding agency supported the collection of data, collection and transportation of the blood samples and the processing of samples in the laboratory.

\section{Availability of data and materials}

The datasets used and/or analyzed during the current study are available from the corresponding author on reasonable request.

\section{Authors' contributions}

AMA conceptualized the study, wrote the proposal, supervised data collection, manuscript writing; ARS contributed towards proposal writing, training of data collectors, guided the analysis and manuscript writing; AK supervised the data collection, cleaning of data and conducted analysis and contributed towards manuscript writing, MB helped in data collection, manuscript writing and review; AAH supervised the data collection, manuscript writing and review. All authors read and approved the final manuscript.

\section{Ethics approval and consent to participate}

The study protocol was approved by the Institutional Review Board, King Saud University (E-12-658) and the Institutional Review Board of the Ministry of Health, Dammam (IRB ID MOH0151). Informed and signed consent was received from each participant.

\section{Consent for publication}

Consent for publication for research purpose was taken from the participant.

\section{Competing interests}

The authors declare that they have no competing interests.

\section{Publisher's Note}

Springer Nature remains neutral with regard to jurisdictional claims in published maps and institutional affiliations.

\section{Received: 22 July 2018 Accepted: 15 March 2019}

\section{Published online: 08 April 2019}

\section{References}

1. World Health Organization. Cardiovascular diseases (CVDs) fact sheet (2015). Geneva: WHO. Retrieved at: http://www.who.int/mediacentre/factsheets/ fs317/en/. Accessed 20 January 2016

2. Aljefree N, Ahmed F. Prevalence of cardiovascular disease and associated risk factors among adult population in the Gulf region: a systematic review. Adv Public Health. 2015;2015:23. Article ID 235101. https://doi.org/10.1155/ 2015/235101.

3. Motlagh B, O'Donnell M, Yusuf S. Prevalence of cardiovascular risk factors in the Middle East: a systematic review. Eur J Cardiovasc Prev Rehabil. 2009;16: 268-80. https://doi.org/10.1097/HJR.0b013e328322ca1b.

4. Al-Daghri NM, Al-Attas OS, Alokail MS, et al. Diabetes mellitus type 2 and other chronic non-communicable diseases in the central region, Saudi Arabia (Riyadh cohort 2): a decade of an epidemic. BMC Med. 2011;9:1-6. https://doi.org/10.1186/1741-7015-9-76.

5. Al-Nozha MM, Arafah MR, Al-Mazrou YY, et al. Coronary artery disease in Saudi Arabia. Saudi Med J. 2004;25:1165-71.

6. O'Donnell MJ, Xavier D, Liu L, et al. Risk factors for ischaemic and intracerebral haemorrhagic stroke in 22 countries (the INTERSTROKE study) a case-control study. Lancet. 2010;376:112-23. https://doi.org/10.1016/ S0140-6736(10)60834-3.
7. Yusuf S, Hawken S, Ônpuu S, et al. Effect of potentially modifiable risk factors associated with myocardial infarction in 52 countries (the INTERHEART study): case-control study. Lancet. 2004;11-17(364):937-52.

8. Alsheikh-Ali AA, Omar MI, Raal FJ, et al. Cardiovascular risk factor burden in Africa and the middle east: the Africa Middle East Cardiovascular Epidemiological (ACE) Study. PLoS One. 2014;9:e102830. https://doi.org/10. 1371/journal.pone.0102830.

9. El Bcheraoui C, Memish ZA, Tuffaha M, et al. Hypertension and its associated risk factors in the Kingdom of Saudi Arabia, 2013: a national survey. Int J Hypertens. 2014:564679. https://doi.org/10.1155/2014/564679.

10. Ahmed AA, Alsharief $E$, Alsharief A. Evaluation of risk factors for cardiovascular diseases among Saudi diabetic patients attending primary health care service. Diabetes Metab Syndr Clin Res Rev. 2013;7:133-7. https://doi.org/10.1016/j.dsx.2013.06.012.

11. Koura M, Al-Dabal B, Rasheed P, Al-Sowielem L, Makki S. Prehypertension among young adult females in Dammam, Saudi Arabia/Préhypertension chez des jeunes femmes à Dammam (Arabie saoudite). East Mediterr Health J. 2012;18:728-34

12. Chau JY, Grunseit A, Midthjell K, et al. Sedentary behaviour and risk of mortality from all-causes and cardiometabolic diseases in adults: evidence from the HUNT3 population cohort. Br J Sports Med. 2015:49:737-42. https://doi.org/10.1136/bjsports-2012-091974.

13. Proper Kl, Singh AS, Van Mechelen W, Chinapaw MJ. Sedentary behaviors and health outcomes among adults: a systematic review of prospective studies. Am J Prev Med. 2011;40:174-82. https://doi.org/10.1016/j.amepre.2010.10.015.

14. Petersen CB, Bauman A, Grønbæk M, Helge JW, Thygesen LC, Tolstrup JS. Total sitting time and risk of myocardial infarction, coronary heart disease and all-cause mortality in a prospective cohort of Danish adults. Int J Behav Nutr Phys Act. 2014;11:13. https://doi.org/10.1186/1479-5868-11-13.

15. Al-Hazzaa HM. Health-enhancing physical activity among Saudi adults using the International Physical Activity Questionnaire (IPAQ). Public Health Nutr. 2007:10:59-64. https://doi.org/10.1017/S1368980007184299.

16. Al-Nozha MM, Al-Hazzaa HM, Arafah MR, et al. Prevalence of physical activity and inactivity among Saudis aged 30-70 years: a population-based crosssectional study. Saudi Med J. 2007;28:559-68.

17. Al-Hazzaa HM, Abahussain NA, Al-Sobayel HI, Qahwaji DM, Musaiger AO. Physical activity, sedentary behaviors and dietary habits among Saudi adolescents relative to age, gender and region. Int J Behavioral Nutr Phys Activ. 2011;8:140. https://doi.org/10.1186/1479-5868-8-140.

18. Al-Othaimeen AL, Al-Nazha M, Osman AK. Obesity: an emerging problem in Saudi Arabia. Analysis of data from the National Nutrition Survey. Eastern Mediter Health J. 2007;13:441-8.

19. Wilson PW, D'Agostino RB, Levy D, Belanger AM, Silbershatz H, Kannel WB. Prediction of coronary heart disease using risk factor categories. Circulation. 1998;97:1837-47. https://doi.org/10.1161/01.CIR.97.18.1837.

20. Assmann G, Cullen P, Schulte H. Simple scoring scheme for calculating the risk of acute coronary events based on the 10-year follow-up of the prospective cardiovascular Münster (PROCAM) study. Circulation. 2002;105:310-5.

21. Conroy R, Pyörälä K. Fitzgerald ae, et al. estimation of ten-year risk of fatal cardiovascular disease in Europe: the SCORE project. Eur Heart J. 2003;24:987-1003.

22. Ridker PM, Buring JE, Rifai N, Cook NR. Development and validation of improved algorithms for the assessment of global cardiovascular risk in women: the Reynolds risk score. JAMA. 2007;297:611-9. https://doi.org/10. 1001/jama.297.6.611.

23. Ridker PM, Paynter NP, Rifai N, Gaziano JM, Cook NR. C-reactive protein and parental history improve global cardiovascular risk prediction the Reynolds risk score for men. Circulation. 2008;118:2243-51. https://doi.org/10.1161/ CIRCULATIONAHA.108.814251.

24. Goff DC, Lloyd-Jones DM, Bennett G, et al. 2013 ACC/AHA guideline on the assessment of cardiovascular risk: a report of the American College of Cardiology/American Heart Association task force on practice guidelines. J Am Coll Cardiol. 2014;63(Pt B):2935-59. https://doi.org/10.1016/j.jacc.2013.11.005.

25. Liau SY, Izham MM, Hassali M, Shafie A. A literature review of the cardiovascular risk-assessment tools: applicability among Asian population. Heart Asia. 2010;2: 15-8. https://doi.org/10.1136/ha.2009.001115 eCollection 2010.

26. Batsis JA, Lopez-Jimenez F. Cardiovascular risk assessment-from individual risk prediction to estimation of global risk and change in risk in the population. BMC Med. 2010:8:29. https://doi.org/10.1186/1741-7015-8-29.

27. Eichler K, Puhan MA, Steurer J, Bachmann LM. Prediction of first coronary events with the Framingham score: a systematic review. Am Heart J. 2007 153(5):722-31, 731.e1-8. https://doi.org/10.1016/j.ahj.2007.02.027. 
28. Sheridan S, Pignone M, Mulrow C. Framingham-based tools to calculate the global risk of coronary heart disease. J Gen Intern Med. 2003;18(12):1039-52 https://doi.org/10.1111/j.1525-1497.2003.30107.x.

29. Al-Humaidi M. Probability of coronary artery disease among patients attending primary health care centers (PHCCS) in Southwest Saudi Arabia. Ethn Dis. 2000;10:350-6.

30. Al-Dahi S, Al-Khashan H, Al Madeer MAM, et al. Assessment of Framingham cardiovascular disease risk among militaries in the Kingdom of Saudi Arabia. Mil Med. 2013;178:299-305.

31. World Health Organization. Obesity: preventing and managing the global epidemic. Report 521 on a WHO Consultation on Obesity. Geneva: World Health Organization; 1997. WHO/NUT/NCD/98.1.

32. World Health Organization. Waist Circumference and Waist-Hip Ratio Report of a WHO 525 Expert Consultation Geneva, 8-11 December 2008. Retrieved at https://apps.who.int/iris/bitstream/handle/10665/44583/9789241501491 eng.pdf? sequence $=1$ on 10 Aug 2016.

33. Lee PH, Macfarlane DJ, Lam TH, Stewart SM. Validity of the International Physical Activity Questionnaire Short Form (IPAQ-SF): a systematic review. Int J Behav Nutr Phys Act. 2011;8:115. https://doi.org/10.1186/ 1479-5868-8-115.

34. International Physical Activity Questionnaire. Guidelines for data processing and analysis of the international physical activity questionnaire (IPAQ). Short and Long forms. 2005. Accessed 8 May 2015.

35. D'Agostino RB Sr, Vasan RS, Pencina MJ, Wolf PA, Cobain M, Massaro JM, Kannel WB. General cardiovascular risk profile for use in primary care: the Framingham heart study. Circulation. 2008;117:743-53. https://doi.org/10. 1161/CIRCULATIONAHA.107.699579.

36. Framingham Heart Study. 2015. Framingham Heart Study. Retrieved December 28, 2014 from https://www.framinghamheartstudy.org/riskfunctions/cardiovascular-disease/10-year-risk.php\#. Accessed 15 June 2015.

37. Patel AV, Bernstein L, Deka A, Feigelson HS, Campbell PT, Gapstur SM, Colditz GA, Thun MJ. Leisure time spent sitting in relation to total mortality in a prospective cohort of US adults. Am J Epidemiol. 2010;172:419-29. https://doi.org/10.1093/aje/kwq155.

38. World Health Organization. In: Mendis S, Puska P, Norrving B, editors. Global Atlas on Cardiovascular disease prevention and control. Geneva: World Health organization in collaboration with the World Heart Federation and World Stroke Organization; 2011. Accessed 5 July 2015.

39. Jousilahti $P$, Vartiainen $E$, Tuomilehto J, Puska P. Sex, age, cardiovascular risk factors, and coronary heart disease a prospective follow-up study of 14786 middle-aged men and women in Finland. Circulation. 1999;99:1165-72.

40. AlQuaiz AM, Siddiqui AR, Qureshi RH, et al. Women health in Saudi Arabia: a review of non-communicable diseases and their risk factors. Pak J Med Sci. 2014;30:422-31.

41. AlHabib KF, Hersi A, AlFaleh $\mathrm{H}$, et al. The Saudi project for assessment of coronary events (SPACE) registry: design and results of a phase I pilot study. Can J Cardiol. 2009;25:e255-8.

42. Mosca L, Barrett-Connor E, Wenger K. Sex/Gender differences in cardiovascular disease prevention. What difference a decade makes. Circulation. 2011;124: 2145-54. https://doi.org/10.1161/CIRCULATIONAHA.110.96879.

43. Carroll MD, Kit BK, Lacher DA. Total and high-density lipoprotein cholesterol in adults: National Health and nutrition examination survey, 2009-2010. NCHS Data Brief. 2012;92:1-8.

44. Thorp AA, Healy GN, Owen N, et al. Deleterious associations of sitting time and television viewing time with cardiometabolic risk biomarkers: Australian diabetes, obesity and lifestyle (AusDiab) study 2004-2005. Diabetes Care. 2010;33:327-34. https://doi.org/10.2337/dc09-0493.

45. Lee M, Flammer AJ, Kim H, et al. The prevalence of cardiovascular disease risk factors and the Framingham Risk Score in Patients Undergoing Percutaneous intervention over the last 17 years by Gender: Time Trend Analysis from Mayo Clinic PCI registry. J Prev Med Public Health. 2014;47: 216-29. https://doi.org/10.3961/jpmph.2014.47.4.216.

46. Brindle PM, McConnachie A, Upton MN, et al. The accuracy of Framingham risk score in different socioeconomic groups: a prospective study. $\mathrm{Br} J \mathrm{Gen}$ Pract. 2005;55:838-45.

47. Van Kempen BKH, Ferket BS, Kavousi M, et al. Performance of Framingham cardiovascular disease (CVD) predictions in the Rotterdam Study taking into account competing risks and disentangling CVD into coronary heart disease (CHD) and stroke. Int J Cardiology. 2014;171:413-8. https://doi.org/10.1016/j. ijcard.2013.12.036
48. Lopez-Jimenez F, Batsis JA, Roger VL, et al. Trends in 10-year predicted risk of cardiovascular disease in the United States, 1976-2004. Circ Cardiovasc Qual Outcomes. 2009;2:443-50.

49. Owen N. Sedentary behavior: Understanding and influencing adults' prolonged sitting time. Prev Med. 2012;55:535-9. https://doi.org/10.1016/j. ypmed.2012.08.024.

50. AlQuaiz JM, Kazi A, Qureshi R, Siddiqui AR, Jamal A, Shaik SA. Physical Activity and Cardiovascular disease risk among women in Riyadh, Kingdom of Saudi Arabia. Women Health. 2015;55:103-17. https://doi.org/10.1080/ 03630242.2014.972020

51. Dunstan DW, Salmon J, Owen N, et al. AusDiab Steering Committee. Associations of TV viewing and physical activity with the metabolic syndrome in Australian adults. Diabetologia. 2005:48:2254-61. https://doi. org/10.1007/s00125-005-1963-4.

52. Dunstan DW, Kingwell BA, Larsen $R$, et al. Breaking up prolonged sitting reduces postprandial glucose and insulin responses. Diabetes care. 2012;35: 976-83. https://doi.org/10.2337/dc11-1931.

53. Al-Zalabani AH, Al-Hamdan A, Saeed AA. The prevalence of Physical activity and its socioeconomic correlates in Kingdom of Saudi Arabia: A cross sectional population based national survey. J Taibah Univ Med Sci. 2015;10: 208-15. https://doi.org/10.1016/j.jtumed.2014.11.001.

54. Midhet F, Al-Mohaimeed AR, Sharaf F. Dietary practices, physical activity and health education in Qassim Region of Saudi Arabia. Int J Health Sci (Qassim). 2010;1:3-10

55. Arsenault BJ, Rana JS, Lemieux I, et al. Physical activity, the Framingham risk score and risk of coronary heart disease in men and women of the EPICNorfolk study. Atherosclerosis. 2010;209:261-5. https://doi.org/10.1016/j. atherosclerosis.2009.08.048.

56. Khera AV, Emdin CA, Drake I, et al. Genetic risk, adherence to healthy life style, and coronary disease. N Engl J Med. 2016;375:2349-58.

57. Soofi MA, Youssef MA. Prediction of 10-year risk of hard coronary events among Saudi adults based on prevalence of heart disease risk factors. J Saudi Heart Assoc. 2015;27:152-9.

58. Setayeshgar S, Whiting SJ, Pahwa P, Vatanparast H. Predicted 10-year risk of cardiovascular disease among Canadian adults using modified Framingham risk score in association with dietary intake. Appl Physiol Nutr Metab. 2015; 40:1068-74.

59. Schlendorf $\mathrm{KH}$, Nasir K, Blumenthol RS. Limitations of Framingham risk score are now much clearer. Prev Med. 2009:48:115-6.

60. Svensson AC, Forsberg JS, Seblova D et al. Residential 602 area and physical activity: A multi-level study of 68,000 adults in Stockholm County. Scandinavian Journal of Public Health. 2017;45(1):25-32.

61. Abazid R, Al Saqqa H, Smettei O. Analysis of three risk stratification systems in a Saudi population. J Saudi Heart Assoc. 2017;29:96-101.

62. AL-Ahmadi H. Martin Roland; quality of primary health care in Saudi Arabia: a comprehensive review. Int J Qual Health Care. 2005;17:331-46.

63. Celis-Morales CA, Perez-Bravo F, Ibañez L, Salas C, Bailey MES, Gill JMR. Objective vs. Self-Reported Physical Activity and Sedentary Time: Effects of Measurement Method on Relationships with Risk Biomarkers. PLoS ONE. 2012;7:e36345. https://doi.org/10.1371/journal.pone.0036345.

64. Stuart-Shor EM, Berra KA, Kamau MW, Kumanyika SK. Behavioral strategies for cardiovascular risk reduction in diverse and underserved racial/ethnic groups. Circulation. 2012;125(1):171-84 https://doi.org/10.1161/ CIRCULATIONAHA.110.968495.

65. Ferket BS, van Kempen BJ, Hunink MG, et al. Predictive value of updating Framingham risk scores with novel risk markers in the U.S. general population. PLoS One. 2014;9(2):e88312. https://doi.org/10.1371/journal. pone.0088312.

66. AlAhmed Z, Lobelo F. Physical activity promotion in Saudi Arabia: A critical role for clinicians and the health care system. J Epidemiol Global Health. 2018;7 Supplement 1:S7-S15. 